\title{
Optimum conditions of killer toxins produced by Torulaspora delbrueckii and Wickerhamomyces anomalus and their action as antifungal agents
}

Najwa Mohammed Jameel Ali Abu-Mejdad', Abdullah H. Al-Saadoon², Adnan I. Al-Badran and Mohammed Hussein Minati ${ }^{3^{*}}$ (D)

\begin{abstract}
Background: This study was conducted to estimate the antifungal activity and efficiency of purified killer toxins (TK and WK) produced by Torulaspora delbrueckii and Wickerhamomyces anomalus as alternative drugs of resistant strains against several pathogenic fungi (Candida albicans, Aspergillus niger, and Aspergillus flavus). A specific focus was on the antifungal activity of such purified proteins by using a simple and economical tools under controlled conditions of fermentations.

Results: The results showed that the optimum conditions of these experiments were detected at $30{ }^{\circ} \mathrm{C}, 150 \mathrm{rpm}, \mathrm{pH}$ 4.5, 3 days incubation period and by using one culture medium (yeast malt extract broth with 2\% SDS). The extracted crude toxin had an excellent effect on Candida albicans, Aspergillus niger, and Aspergillus flavus. The inhibition zone values were 35 and $30 \mathrm{~mm}$ for WK and TK, respectively, against Candida albicans. While the lowest values of inhibition zone were recorded at $25 \mathrm{~mm}$ for WK and $18 \mathrm{~mm}$ for TK against Aspergillus flavus. The WK killer toxins were in general more active against the three clinical strains compared to the TK that had the lowest inhibitory effect.

Conclusion: This study is conducted for the first time in Iraq to determine the optimum conditions for producing two types of killer toxins and testing their antifungal activity. The optimal killer activity was obtained at low pH and mesophilic temperature. The two yeast strains had a good role in the reduction of radial growth of tested pathogenic fungi
\end{abstract}

Keywords: Alternative drugs, Killer toxins, Primary screening, Optimum condition, Yeasts, Torulaspora delbrueckii, Wickerhamomyces anomalus

\section{Background}

More than 1500 species of yeast have been described so far, many of them have been used in various fermentation processes (Kręgiel et al. 2017). Numerous species of yeasts have been reported to produce toxic proteins called exotoxin or mycocins against several pathogenic yeasts (Abu-Mejdad et al. 2020; Ferraz et al. 2016). For example, Torulaspora delbrueckii (a species of yeasts belongs to the family of Saccharomycetaceae) and Wickerhamomyces anomalus

\footnotetext{
*Correspondence: abo_azher70@yahoo.com

${ }^{3}$ Biologu Department, College of Education, Qurna, University of Basrah, Basrah, Iraq

Full list of author information is available at the end of the article
}

(belongs to the family of Wickerhamomyceteae) have been reported to produce strong and active toxic proteins or glycoproteins as killer toxins. These antimicrobial substances can play an important role in the inhibition growth of different genera of yeasts (Becker and Schmitt, 2017; Weiler and Schmitt, 2003). The production of killer toxins was firstly described in 1963 for Saccharomyces cerevisiaein; after that, the activity of killer toxins has been reported in 100 yeast species belonging to more than 20 genera (Maturano et al. 2012). The mode of action of these mycocins may be related to several mechanisms that involve DNA damage or inhibition of DNA replication, attacking the cell membranes of targeted yeast cells and pore 
formation. The pore formation can lead to cell death due to changes in the permeability of cytoplasmic membrane, loss of potassium ions, and energy (Camilli and Quintin, 2018).

According to Ruyters et al. (2015), there are three basic phenotypes for killer toxin production. First, killer strains that produce both a specific killer factor and resist to this toxin. Second, neutral strains that resist to one or more killer toxins and do not produce any killer factor. Third, sensitive strains that are totally susceptible to killer toxin causing inhibition of macromolecule synthesis and cell disruption resulting in cell death indicated the interactions between yeasts and filamentous fungi (killer-sensitive K-S strains). The K-S strains form killer factors, which are also sensitive to other killer yeasts (Chen and Chou, 2017; Marquina et al. 2002)

Although yeasts are known in their biological roles in the environment, however, there are much more actions of yeast modes have not been discovered in particular environments as well as their behaviors as antifungals against other organisms (Brauer et al. 2019; Ferraz et al. 2016)

According to Ruyters et al. (2015), sensitive cells have been reported to be killed by the viral K1 toxin of S. cerevisiae due to the function disruption of cytoplasmic membranes and the formation of lethal ion channels. Other behaviors of toxins, such as the viral K28 toxin of S. cerevisiae and the plasmid-driven killer toxin of K. lactis, result in early S phase or cell cycle arrestin G1, respectively (Weiler and Schmitt, 2003). In this perspective, the experiments of sensitive fermentation and killers have come to be relevant. On the other hand, inconsistent consequences have been stated concerning the appropriate preliminary killer/sensitive proportion that allows killer yeasts to prevail fermentation environments. As stated by Maturano et al. (2012), when the temperature of incubation is ranged between 18 and $28^{\circ} \mathrm{C}$, the expression of Saccharomyces cerevisiae killer toxin would be allowed. A number of studies informed that toxins produced by Saccharomyces and other killer genera ordinarily become inactive at higher temperatures (35 or 40 $\left.{ }^{\circ} \mathrm{C}\right)$. Many species of yeasts have been reported their incubation period affecting on the production of antifungal agents (Samoticha et al., 2019)

The majority of killer yeasts have various characteristics that make them effective bio-agents in the conservation of fruits and vegetables. These killer yeasts have simple nutritional requirements, and are consequently effortlessly produced in great-scales. Furthermore, they do not host pathogenic or toxic abilities, in contradiction of filamentous fungi (Çorbacı and Uçar, 2017a; Mukherjee et al. 2020)

The current study was conducted to examine the production, detection, and testing the killer activities of mycocin produced by Torulaspora delbrueckii and Wickerhamomyces anomalus against fungi by using simple and economical tools under controlled conditions of fermentations.

\section{Methods}

Maintenance of microorganisms

Torulaspora delbrueckii and Wickerhamomyces anomalus strains were isolated and identified previously from soil samples by Abu-Mejdad (2019) to be used for producing killer toxins. Yeast cells were grown and maintained in slant medium of Yeast Extract-Peptone Dextrose agar (YEPD) containing $2 \%$ dextrose, $2 \%$ peptone, $1 \%$ yeast extract, and $2 \%$ agar at $4{ }^{\circ} \mathrm{C}$ (Himedia, India). Pathogenic strains (Candida albicans, Aspergillus niger, Aspergillus flavus) were obtained from the Mycology Lab., College of Science, University of Basrah, Basrah, Iraq. They were originally isolated from clinical samples and their identification and characterization were done according to morphological, biochemical, and molecular methods by using ITS1-ITS2 rDNA region, following Mirhendi et al. (2006). All isolates were sub-cultured and maintained on YEPD for further use.

\section{Effects of $\mathrm{pH}$, incubation temperature, stimulators, rpm, and period of incubation on killer toxin production Inoculum preparation and production medium}

Three discs with $6 \mathrm{~mm}$ in diameter of tested yeasts (Torulaspora delbrueckii and Wickerhamomyces anomalus) were transferred from the periphery of 2 days old culture to produce toxins and then added into the Yeast Extract Peptone Dextrose broth (YEPD). After inoculation, the flasks were incubated in different conditions.

In order to detect the optimum conditions for killer toxin production by Torulaspora delbrueckii and Wickerhamomyces anomalus, different factors were examined. Briefly, YEPD was prepared under various $\mathrm{pH}$ values $(6.5,6,5.5,5$, and 4.5$)$, different periods of incubation (7, $6,5,4$, and 3) days, various rotations of liquid culture broth $(200,180,160,150$, and 120) rpm, different temperatures of incubation during fermentation $(15,20,25$, 30 , and 37$){ }^{\circ} \mathrm{C}$, and different stimulators were added to broth culture (Tween80 2\% (BDH, England), glycerol 2\% (BDH, England), DMSO 2\% (Merk, Germany), ammonium sulfate 2\% (Merk, Germany) and SDS 2\% (Fisher Biotech., USA) for extracting crude toxins. The solution was evaporated at room temperature until dry and sterilized by Millipore filter paper $0.45 \mu$. The crude extract then kept in closed vials and reserved until used for susceptibility test of killer toxins (Al-Qaysi et al. 2017a).

\section{Primary susceptibility test of extracted crude killer toxins as antifungal (killer assay) \\ Crude toxins extraction}

The test of primary screening of crude killer toxins was performed in different conditions against three clinical fungal isolates Candida albicans, Aspergillus niger, and Aspergillus flavus. The period of incubation was 2 days for candida albicans and 5 days for the filamentous fungi. 
A $100 \mu \mathrm{l}$ from the suspension of yeast (Candida albicans) and filamentous fungi (Aspergillus niger and Aspergillus flavus) was added to the methylene blue plates for fungi, then spread by L-shaped glass spreader. The plates were left to dry for $15 \mathrm{~min}$ at room temperature and then wells with $6 \mathrm{~mm}$ diameter were made using a sterile cork-borer. After that, a $100 \mu \mathrm{l}$ of crude killer toxins at concentration $200 \mathrm{mg} / \mathrm{ml}$ D.W. was added individually to each well and incubated at 37 ${ }^{\circ} \mathrm{C}$ for 2 and 5 days for yeast and filamentous fungi, respectively. The results were calculated by measuring the inhibition zone diameter in millimeters. The positive control used in this experiment was Nystatin at concentration $200 \mathrm{mg} / \mathrm{ml}$, which performed according to Serban et al. (2011).

\section{Purification of killer toxins}

The methods of purifying killer toxins were conducted according to Taguchi (1995) and Villalba et al. (2016).

\section{Susceptibility test of purified killer toxins extracted as antifungal} The susceptibility test of the purified toxins was performed as described in (Al-Hilfy and Abu-Mejdad, 2014). Briefly, a $100 \mu \mathrm{l}$ was taken from the suspension of pathogenic fungal strains, and the suspension of fungi then added to the Sabourauds agar and spread by Lshaped glass spreader. The plates were left to dry for 15 $\mathrm{min}$ at room temperature, and then wells with $6 \mathrm{~mm}$ diameter were made using a stirle cork-borer. After that, a $100 \mu$ of killer toxins (TK, WK) at concentration 200 $\mathrm{mg} / \mathrm{ml} \mathrm{DW}$ was added individually to each well and incubated at $37^{\circ} \mathrm{C}$ for 5 days. The results were read by measuring the inhibition zone diameter in $\mathrm{mm}$.

\section{Statistical analysis}

The antifungal activity was analyzed statistically using one-way ANOVA in SPSS program version 20 to determine the level of significant difference $(P<0.05)$ in the effect of two purified toxins against clinical strains.

\section{Results}

Production of killer toxins by Torulaspora delbrueckii and Wickerhamomyces anomalus under different conditions

The effect of various $\mathrm{pH}$ value on the activity of killer toxins were examined by using an agar diffusion well bioassay. The optimum inhibitory for crude killer toxins, which extracted from the two subjected yeasts against all tested pathogenic agents was recorded at $\mathrm{pH}$ value of 4.5. Generally, the effect of killer toxins produced by Wickerhamomyces anomalus had a higher effect on all tested pathogenic fungi in comparison to the killer toxins produced by Torulaspora delbrueckii.

The results in Fig. 1 show the mean diameters of inhibition zones under different $\mathrm{pH}$ values for the crude

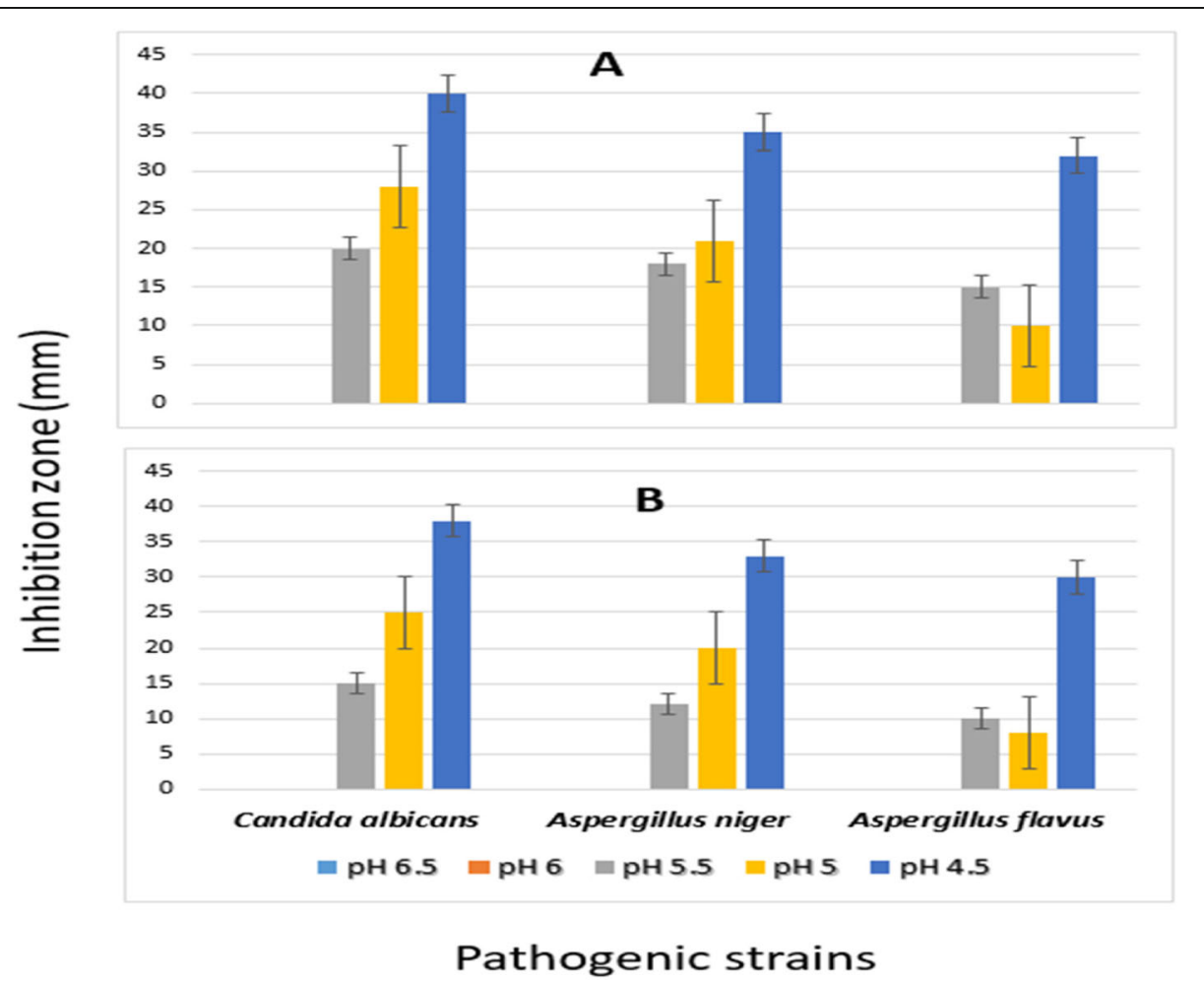

Fig. 1 Effects of five different $\mathrm{pH}$ of liquid fermentation broth on the production and killing activity of killer toxin produced by Wickerhamomyces anomalus (a) and Torulaspora delbrueckii (b) against pathogenic fungi. The killer activity was measured by the means of inhibition zone around the wells 
killer toxins of Wickerhamomyces anomalus (Fig. 1a) and Torulaspora delbrueckii (Fig. 1b). The clear zone diameters of Candida albicans, Aspergillus niger, and Aspergillus flavus were 40, 35, and 32, and 38, 33, and $30 \mathrm{~mm}$ effected by killer toxins produced by Wickerhamomyces anomalus and Torulaspora delbrueckii, respectively.

Two $\mathrm{pH}$ values (6 and 6.5) in the fermentation broth for the two yeasts showed no effect as antifungal on all the tested pathogenic fungi, as the values of inhibition zones were 0 . The results also showed that the low acidity (4.5) reduced the killer activity, while the high acidity had increased it.

Five periods of incubation $(7,6,5,4$, and 3$)$ days were tested for the two subjected yeasts during fermentation process. The results showed that the 3days was the best incubation period in fermenting medium to produce killer toxins by Wickerhamomyces anomalus and Torulaspora delbrueckii. The effect of killer toxins produced by Wickerhamomyces anomalus was higher than Torulaspora delbrueckii when measuring the rate of inhibition diameters on the studied pathogenic fungi in the same period

The results in Fig. 2 show the effect of periods on killer toxin produced by the two yeasts. The 3 -day period was the best. The killer toxins produced by Wickerhamomyces anomalus (Fig. 2a) during this period gave inhibition rates at 50,43 , and $40 \mathrm{~mm}$, while toxins produced by Torulaspora delbrueckii (Fig. 2b) were at 46, 40, and $37 \mathrm{~mm}$ toward Candida albicans, Aspergillus niger, and Aspergillus flavus, respectively. On the other hand, a 7-day period for both tested yeasts gave the least inhibition diameters since the killer toxins produced by Wickerhamomyces anomalus during this period had inhibition rates of 15, 13, and $10 \mathrm{~mm}$, while the toxins produced by Torulaspora delbrueckii were 10, 8, and $6 \mathrm{~mm}$ towards Candida albicans, Aspergillus niger, and Aspergillus flavus, respectively.

A 5 rotation rate of $200,180,160,150$, and $120 \mathrm{rpm}$ of liquid culture broth were used in this experiment. The results in the Fig. 3 also show that the rotation process $(\mathrm{rpm})$ at a rate of 150 cycles per minute during the fermentation period for both tested yeasts gave raw killer toxins with high inhibitory efficacy. The killer toxins produced by Wickerhamomyces anomalus (Fig. 3a) gave inhibition rates at 45,40 , and $30 \mathrm{~mm}$, while the toxins produced by Torulaspora delbrueckii Fig. 3b display the inhibition rates at 35, 32, and $25 \mathrm{~mm}$ toward Candida albicans, Aspergillus niger and Aspergillus flavus, respectively. In comparison, no inhibitory activity was shown for the killer toxins produced by the two yeasts against the tested isolates during the rotation process, which reached to 120 and 200, as shown in Fig. 3a, b.

A 5 temperature degrees $(15,20,25,30$, and 37$){ }^{\circ} \mathrm{C}$ were examined during this experiment. The results in Fig. 4 show that the $30{ }^{\circ} \mathrm{C}$ as an incubation temperature

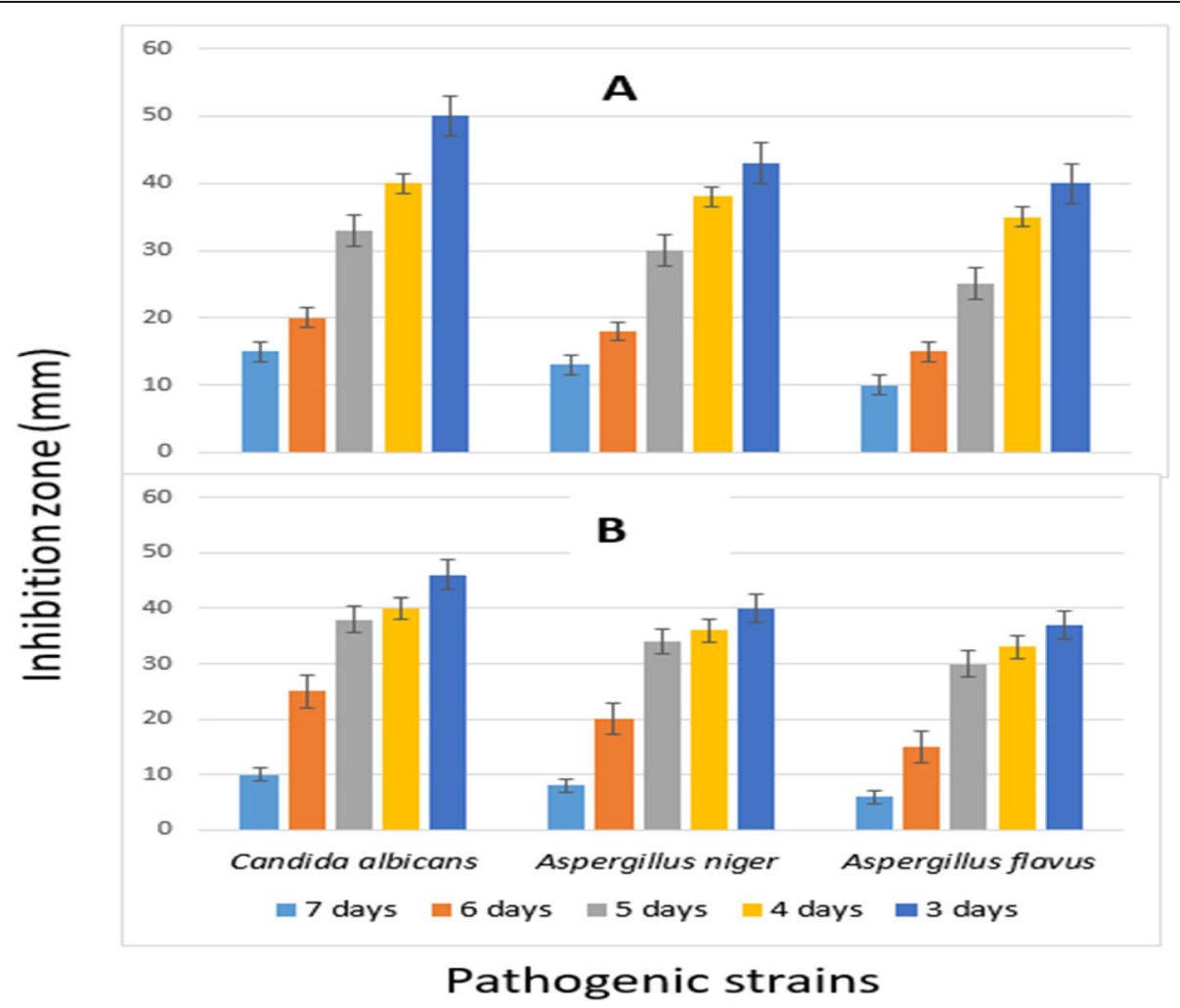

Fig. 2 Effects of fermentation period on the production and killing activity of killer toxin produced by Wickerhamomyces anomalus (a) and Torulaspora delbrueckii (b) against pathogenic fungi. The killer activity was measured by the means of inhibition zone around the wells 


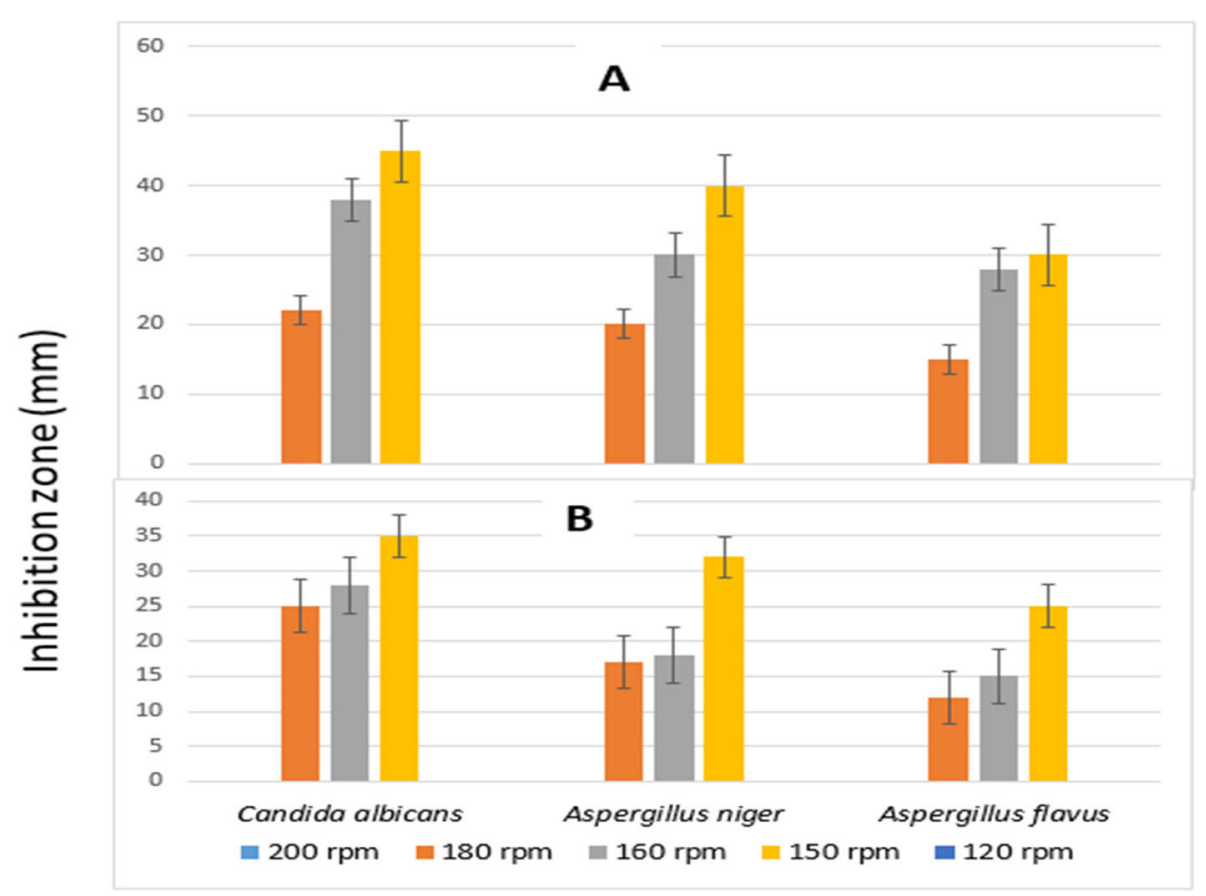

Pathogenic strains

Fig. 3 Effects of the five different rotations per minutes during fermentation period on the production and killing activity of killer toxin produced by Wickerhamomyces anomalus (a) and Torulaspora delbrueckil (b) against pathogenic fungi. The killer activity was measured by the means of inhibition zone around the wells

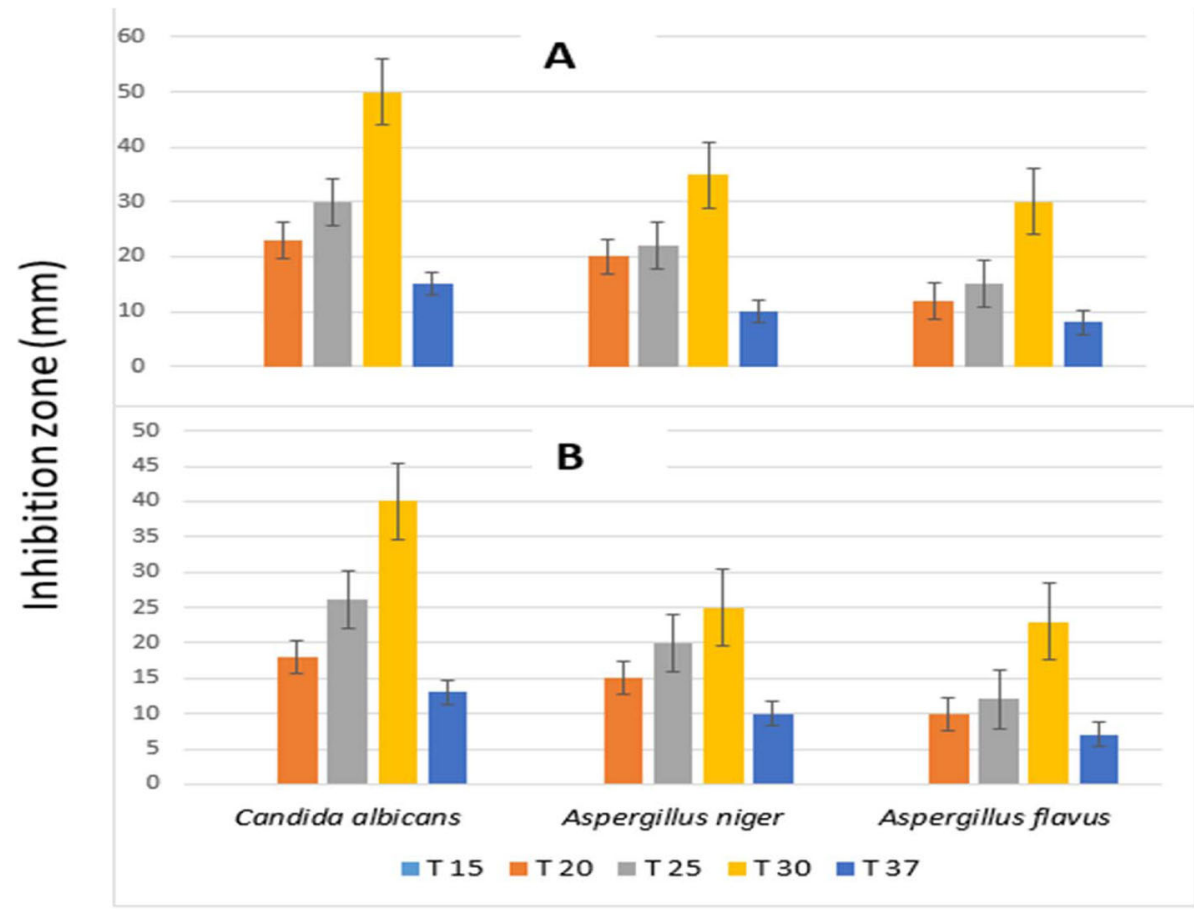

\section{Pathogenic strains}

Fig. 4 Effects of the five different temperature during fermentation period on the production and killing activity of killer toxin produced by Wickerhamomyces anomalus (a) and Torulaspora delbruecki (b) against pathogenic fungi. The killer activity was measured by the means of inhibition zone around the wells 
during the fermentation period of both tested yeasts gave raw killer toxins with high inhibitory efficacy. The killer toxins produced by Wickerhamomyces anomalus, Fig. 4a, showed inhibition rates at 50, 35, and $30 \mathrm{~mm}$, while the toxins produced by Torulaspora delbrueckii (Fig. 4b) were at 40, 25, and $23 \mathrm{~mm}$ toward Candida albicans, Aspergillus niger, and Aspergillus flavus, respectively. Oppositely, no inhibitory activity was shown by the killer toxins produced by the two yeasts with regard to the tested isolates during the temperature of 15 ${ }^{\circ} \mathrm{C}$, as shown in Fig. 4a, b.

A 5 stimulators (Tween $802 \%$, glycerol 2\%, DMSO 2\%, Ammonium sulfate $2 \%$ and SDS $2 \%$ in liquid culture medium were added to broth culture in this experiment. Accordingly, the results in Fig. 5a, b showed that the SDS was the best stimulator for producing killer toxins in the fermentation medium of Wickerhamomyces anomalus and Torulaspora delbrueckii.

The effect of killer toxins produced by the yeast Wickerhamomyces anomalus was higher than Torulaspora delbrueckii when measuring the rates of inhibition diameters on the studied pathogenic fungi.

The results in Fig. 5 illustrate that the effect of stimulators on the production of killer toxins from the subjected yeasts. The SDS was the best in giving killer toxins produced by Wickerhamomyces anomalus, Fig. 5a, during this period, as the inhibition diameters were 46, 40, and $34 \mathrm{~mm}$, while toxins produced by Torulaspora delbrueckii (Fig. 5b) had inhibition diameters at 40, 38, and $35 \mathrm{~mm}$ towards Candida albicans, Aspergillus niger, and Aspergillus flavus, respectively.

For comparison, the Tween 80 stimulating substance for both tested yeasts gave the lowest inhibition diameters of 20,18, and $15 \mathrm{~mm}$ for the killer toxins produced by Wickerhamomyces anomalus, while toxins produced by Torulaspora delbrueckii had 18, 15, and $14 \mathrm{~mm}$ towards Candida albicans, Aspergillus niger, and Aspergillus flavus, respectively, as shown in Fig. 5a, b.

Note: The results of isolation and purification of these proteins have been published by the same authors of the current study (Abu-Mejdad et al. 2020).

\section{Killer assay of TK and WK}

The antifungal activity of TK and WK compounds at $200 \mathrm{mg} / \mathrm{ml}$ was tested against Candida albicans, Aspergillus niger, and $A$. flavus. The results showed that the WK compound had the higher inhibitory effect against all tested isolates compared to the TK. The results were also compared with the positive control compounds (Nystatine) as an antifungal compound, both were used at $200 \mathrm{mg} / \mathrm{ml}$ concentration as shown in Table 1 and Figs. 6 and 7.

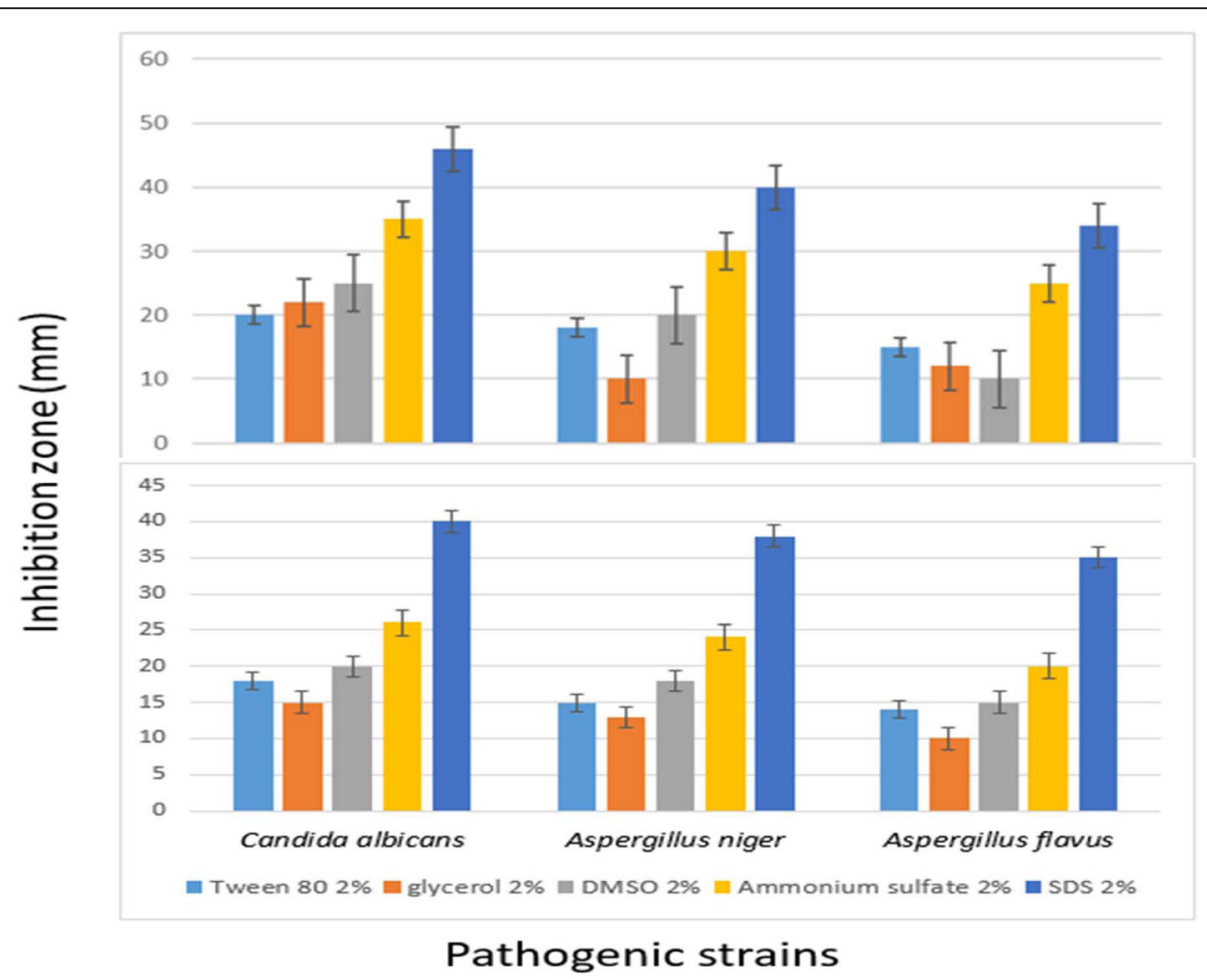

Fig. 5 Effects of the five stimulators added to YPD broth separately in concentration $2 \%$ on the production and killing activity of killer toxin produced by Wickerhamomyces anomalus (a) and Torulaspora delbrueckii (b) against pathogenic fungi. The killer activity was measured by the means of inhibition zone around the wells 
Table 1 Inhibition zone diameters (killer assay) of WK and TK against fungal clinical isolates

\begin{tabular}{llll}
\hline No. & Fungal species & \multicolumn{2}{l}{ Inhibition zone $(\mathrm{mm})$} \\
\cline { 3 - 4 } & & WK (mean \pm SD) & TK (mean \pm SD) \\
\hline 1 & Candida albicans & $35 \pm 2$ & $30 \pm 2$ \\
2 & Aspergillus niger & $28 \pm 2$ & $20 \pm 2$ \\
3 & Aspergillus flavus & $25 \pm 2$ & $18 \pm 2$ \\
4 & Nystatine & 0 & 0 \\
\hline
\end{tabular}

The WK and TK toxins with a concentration of 200 $\mathrm{mg} / \mathrm{ml}$ were tested against three clinical isolates. In general, the results showed that the effect of WK was higher than TK.

\section{Discussion}

Different $\mathrm{pH}$ values $4,4.5,5.5,6$, and 6.5 were used in the culture media showed that the concentration of $\mathrm{pH}$ 4.5 had the highest growth rate. While, the growth was decreased with the increasing of $\mathrm{pH}$ values, this result is concordant with Banjara et al. (2016), who tested the killer activity of 23 strains against C. albicans and C. tropicalis, and noticed that there was no killer activity for any strain at $\mathrm{pH} \geq 6.5$ or at $\geq 35^{\circ} \mathrm{C}$.

The temperature was an another factor to impact the production of enzymes, since the growth at 22, 25, 30, and $37{ }^{\circ} \mathrm{C}$ gave varied amount of production enzymes for the killer toxins with a maximum level of growth rate observed at $30{ }^{\circ} \mathrm{C}$. This result is similar to the finding reported by Al-Qaysi et al. (2017b), who studied the effects of temperature and the production of killer toxins against several pathogenic microorganisms, such as $C$. albicans, C. neoformans Staphylococcus aureus, and others. Their results confirmed that the ideal inhibitory influence of killer toxin was at $\geq 25{ }^{\circ} \mathrm{C}$.

The incubation time in fermentation media was monitored at 72,96 , and $168 \mathrm{~h}$ post inoculation. The result is in concord with the finding of Thammasittirong et al. (2013), who reported that the time was accelerated the vegetative phase of yeasts and encouraged them to reach the production phase at $72 \mathrm{~h}$. To guarantee the efficient production and supply of oxygen to yeast, the rotation rate was tested at 120,150, 180, and $200 \mathrm{rpm}$. The production rate was stimulated at highest level with 150 rpm. Culture media was also supplemented with sodium dodecyl sulphate (SDS) at concentration of $2 \%$, which enhanced the growth rate. This may be attributed to the efficiency of this medium that contains nitrogen and carbon sources, which are used by the yeasts, similar explanation was giving by Çorbacı and Uçar (2017b). Besides, the addition of SDS and the detergent that destroys yeast wall and release killer toxin intracellular production. According to Grzegorczyk et al. (2017), crude killer toxins have the ability to counteract the growth of bacteria and yeasts through pore formation by hydrolytic enzymes production. The toxin binds to its specific receptors on the surfaces of the bacterial and yeast cell walls, then forms pores to release the contents

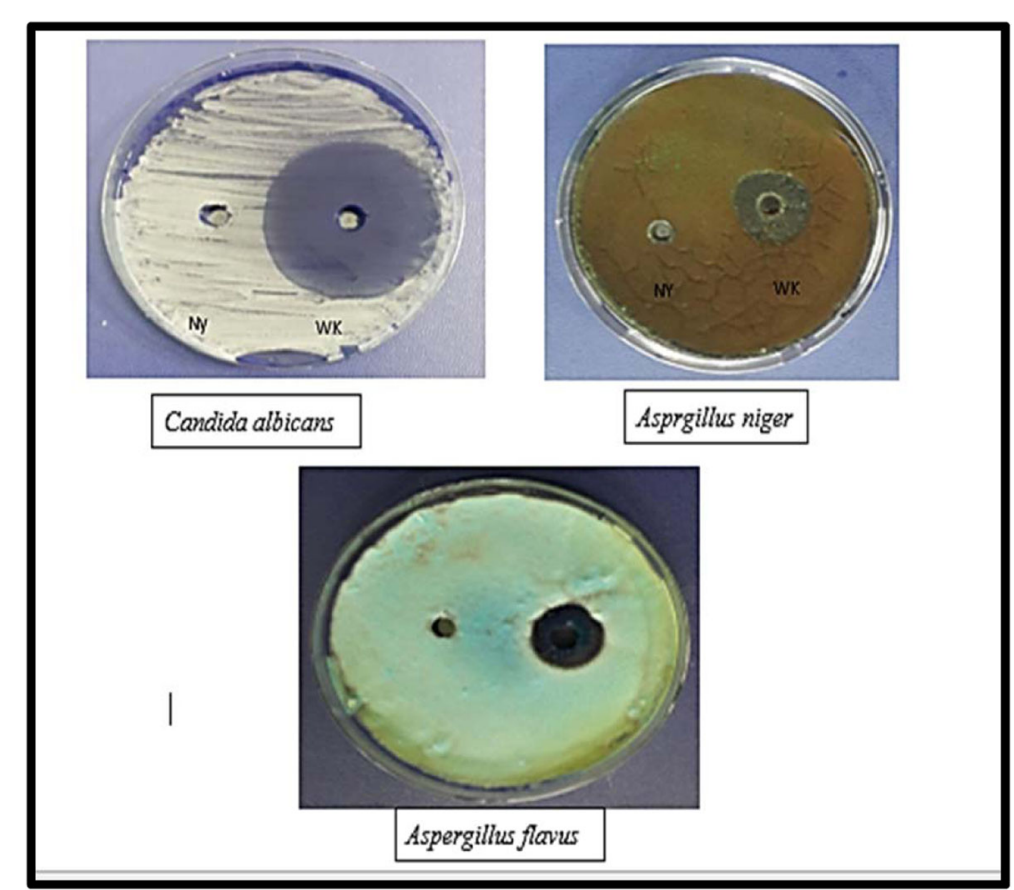

Fig. 6 The killer assay of WK for Wickerhamomyces anomalus against Candida albicans, Aspergillus niger, and Aspergillus flavus at concentration of $200 \mathrm{mg} / \mathrm{ml}$ 


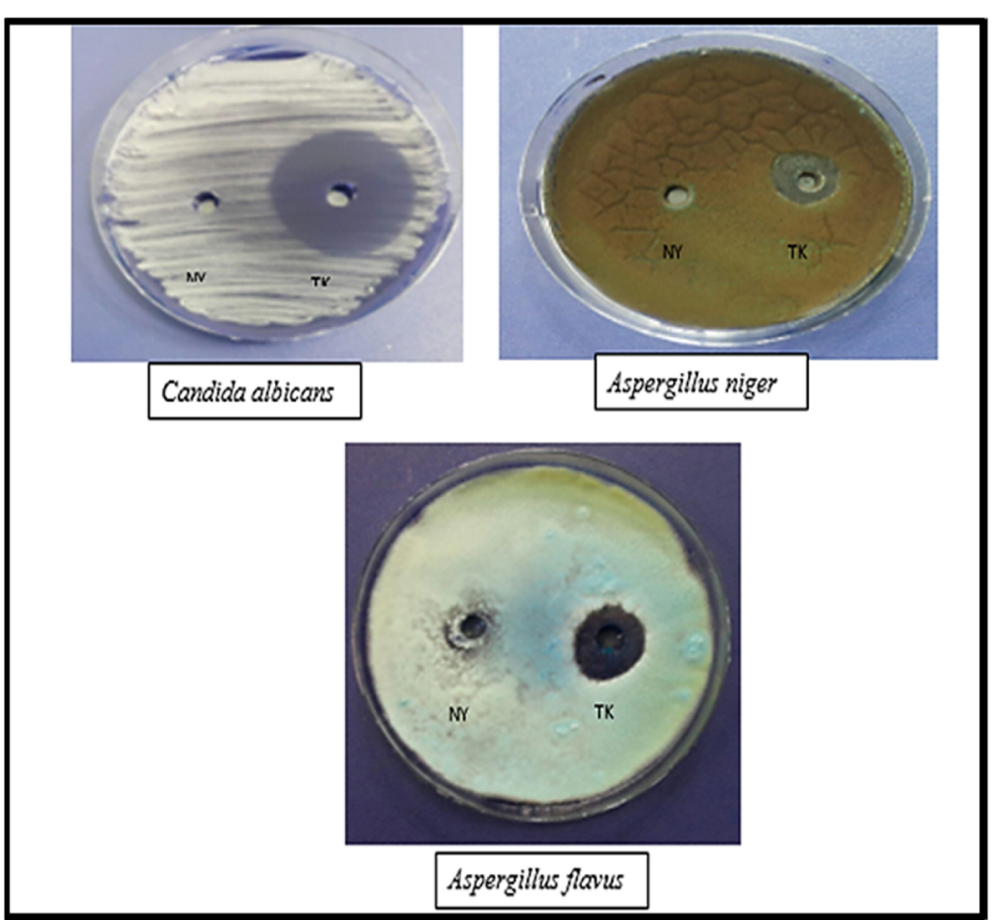

Fig. 7 The killer assay of TK for Torulaspora delbrueckii against Candida albicans, Aspergillus niger, and Aspergillus flavus at concentration of $200 \mathrm{mg} / \mathrm{ml}$

inside the target cells leading to death. This can be attributed to the different mechanism actions reported by Becker and Schmitt (2017). In terms of K28, it has a specific primary receptor in the yeast cell wall, which allows rapid $\mathrm{K} 28$ absorption via an energy-independent binding mechanism. Afterward, $\alpha-1,3-$ or $\alpha-1,2-$ mannotriose side-chains of a $185 \mathrm{kDa}$ cell wall mannoprotein were identified as primary K28 receptor and cell wall binding sites. In contrast, Vadasz et al. (2000) stated that the ionophoric killer toxin (K2) has the ability of killing cells by causing shrinkage as a characteristic of cytosol efflux, which can be seen clearly by electron microscope. The cytosolic efflux and cell death are the results of initial interaction between yeast toxin and specific cell wall receptors, followed by the formation or activation of endogenous ion channels in the plasma membrane of target cells (Ahmed et al. 1999).

\section{Conclusion}

The results revealed that the Torulaspora delbrueckii and Wickerhamomyces anomalus secreted killer toxins. The optimal killer activity was obtained at low $\mathrm{pH}$ and mesophilic temperature. Moreover, the two yeast strains had a good role in reducing the radial growth of tested pathogenic fungi and the medical importance of two killer toxins against fungi was confirmed. Also, different type strains under different conditions in vitro showed variable inhibition zones because the conditions of incubation were very effective in producing the killer toxins.

\section{Abbreviations}

DMSO: Dimethylesulfoxide; G1: (GAP 1) phase; ITS: Internal transcript spacer; K1: Killer toxin 1; K2: Killer toxin 2; K28: Killer toxin 28; K-S strains: Killersensitive; PH: Potential hydrogen; rDNA: Ribosomal deoxy nuclic acid; $\mathrm{S}$ phase: (Synthesis) phase; SDS: Sodium dodcyl sulfate; TK: Torulaspora delbrueckii killer toxin; WK: Wickerhamomyces anomalus killer toxin; YEPD : Yeast Extract-Peptone Dextrose agar

\section{Acknowledgements}

Not applicable

\section{Authors' contributions}

All work was done by NA and MM under supervision and advice of AA and AA. NA have drafted the work, and MM was a major contributor in substantively editing, revising, and writing the manuscript. All authors read and approved the final manuscript.

Funding

Not applicable

Availability of data and materials Not applicable.

Ethics approval and consent to participate Not applicable

\section{Consent for publication}

Not applicable.

\section{Competing interests}

The authors declare that they have no competing interests.

\section{Author details}

'Biology Department, College of Science, University of Basrah, Basrah, Iraq. ${ }^{2}$ Pathological Analyses Department, College of Science, University of Basrah, Basrah, Iraq. ${ }^{3}$ Biologu Department, College of Education, Qurna, University of Basrah, Basrah, Iraq. 
Received: 15 June 2020 Accepted: 23 August 2020

Published online: 04 September 2020

\section{References}

Abu-Mejdad N.M. (2019). Isolation and molecular identification of yeasts, study their potential for producing killer toxins and evaluation of toxins activity against some bacteria and pathogenic fungi. Ph.D. thesis:1-249.

Abu-Mejdad NMJA, Al-Badran Al, Al-Saadoon A (2020) Purification and characterization of two killer toxins originated from Torulaspora delbrueckii (Lindner) and Wickerhamomyces anomalus (EC Hansen) Kurtzman, Robnett, and Basehoar-powers. Bull Natl Res Centre 44:1-8

Ahmed A, Sesti F, llan N, Shih TM, Sturley SL, Goldstein SA (1999) A molecular target for viral killer toxin: TOK1 potassium channels. Cell 99:283-291

Al-Hilfy AA, Abu-Mejdad NM (2014) Evaluate the activity antifungal of aspirin in mice Balb/C infected with Candida albicans in vitro and in vivo. Res J Pharm, Biol Chem Sci 5:1714-1728

Al-Qaysi S.A., Al-Haideri H., Thabit Z.A., Al-Kubaisy W.H.A., Ibrahim J.A. (2017b). Production, characterization, and antimicrobial activity of mycocin produced by Debaryomyces hansenii DSMZ70238. International journal of microbiology 2017.

Al-Qaysi S.A., Al-Haideri H., Thabit Z.A., Al-Kubaisy W.H.A., Ibrahim J.A.A. (2017a). Production, characterization, and antimicrobial activity of mycocin produced by Debaryomyces hansenii DSMZ70238. International journal of microbiology 2017.

Banjara N, Nickerson KW, Suhr MJ, Hallen-Adams HE (2016) Killer toxin from several food-derived Debaryomyces hansenii strains effective against pathogenic Candida yeasts. Int J Food Microbiol 222:23-29

Becker B, Schmitt M (2017) Yeast killer toxin K28: biology and unique strategy of host cell intoxication and killing. Toxins 9:333

Brauer VS, Rezende CP, Pessoni AM, De Paula RG, Rangappa KS, Nayaka SC, Gupta VK, Almeida F (2019) Antifungal agents in agriculture: friends and foes of public health. Biomolecules 9:521

Camilli GTG, Quintin J (2018) The complexity of fungal $\beta$-glucan in health and disease: effects on the mononuclear phagocyte system. Front Immunol 9

Chen PH, Chou J (2017) Screening and identification of yeasts antagonistic to pathogenic fungi show a narrow optimal $\mathrm{pH}$ range for antagonistic activity. Pol J Microbiol 66:101-106

Çorbacı C., Uçar F. (2017b). Production and optimization of killer toxin in Debaryomyces hansenii strains. Brazilian Archives of Biology and Technology 60.

Çorbacı C., Uçar F.B. (2017a). Production and optimization of killer toxin in Debaryomyces hansenii strains. Brazilian Archives of Biology and Technology 60.

Ferraz LP, da Cunha T, da Silva AC, Kupper KC (2016) Biocontrol ability and putative mode of action of yeasts against Geotrichum citri-aurantii in citrus fruit. Microbiol Res 188:72-79

Grzegorczyk M, Żarowska B, Restuccia C, Cirvilleri G (2017) Postharvest biocontrol ability of killer yeasts against Monilinia fructigena and Monilinia fructicola on stone fruit. Food Microbiol 61:93-101

Kręgiel D., Pawlikowska E., Antolak H. (2017). Non-Conventional Yeasts in Fermentation Processes: Potentialities and Limitations. Old Yeasts: New Questions:87.

Marquina D, Santos A, Peinado J (2002) Biology of killer yeasts. Int Microbiol 5: $65-71$

Maturano YP, Nally MC, Toro ME, De Figueroa LIC, Combina M, Vazquez F (2012) Monitoring of killer yeast populations in mixed cultures: influence of incubation temperature of microvinifications samples. World J Microbiol Biotechnol 28:3135-3142

Mirhendi H, Makimura K, Khoramizadeh M, Yamaguchi H (2006) A one-enzyme PCR-RFLP assay for identification of six medically important Candida species. Nippon Ishinkin Gakkai Zasshi 47:225-229

Mukherjee A, Verma JP, Gaurav AK, Chouhan GK, Patel JS, Hesham A (2020) Yeast a potential bio-agent: future for plant growth and postharvest disease management for sustainable agriculture. Appl Microbiol Biotechnol 104: $1497-1510$

Ruyters S, Mukherjee V, Verstrepen KJ, Thevelein JM, Willems KA, Lievens B (2015) Assessing the potential of wild yeasts for bioethanol production. J Ind Microbiol Biotechnol 42:39-48

Samoticha J, Wojdyło A, Chmielewska J, Nofer J (2019) Effect of different yeast strains and temperature of fermentation on basic enological parameters, polyphenols and volatile compounds of Aurore white wine. Foods 8:599
Şerban E, lonescu M, Matinca D, Maier CS, Bojiță MT (2011) Screening of the antibacterial and antifungal activity of eight volatile essential oils. Farmacia 59:440-446

Taguchi S (1995) Communication between protease and protease inhibitor in the Streptomyces world. Actinomycetologica 9:216-227

Thammasittirong S, Thirasaktana T, Thammasittirong A, Srisodsuk M (2013) Improvement of ethanol production by ethanol-tolerant Saccharomyces cerevisiae UVNR56. SpringerPlus 2:583

Vadasz A, Jagganath D, Pretorius I, Gupthar A (2000) Electron microscopy of the K2 killer effect of Saccharomyces cerevisiae T206 on a mesophilic wine yeast. Antonie Van Leeuwenhoek 78:117-122

Villalba ML, Sáez JS, del Monaco S, Lopes CA, Sangorrín MP (2016) TdKT, a new killer toxin produced by Torulaspora delbrueckii effective against wine spoilage yeasts. Int J Food Microbiol 217:94-100

Weiler F, Schmitt MJ (2003) Zygocin, a secreted antifungal toxin of the yeast Zygosaccharomyces bailii, and its effect on sensitive fungal cells. FEMS Yeast Res 3:69-76

\section{Publisher's Note}

Springer Nature remains neutral with regard to jurisdictional claims in published maps and institutional affiliations.

\section{Submit your manuscript to a SpringerOpen ${ }^{\circ}$ journal and benefit from:}

- Convenient online submission

- Rigorous peer review

- Open access: articles freely available online

- High visibility within the field

- Retaining the copyright to your article

Submit your next manuscript at $>$ springeropen.com 